\title{
Vibrotactile sense and hand symptoms in blue collar workers in a manufacturing industry
}

\author{
Bo T Flodmark, Göran Lundborg
}

\begin{abstract}
Objectives-To study whether vibrotactile sense combined with questionnaires (subjective complaints) and a clinical examination (including scoring of the Stockholm workshop scale (sensorineural staging)) could serve as a screening procedure, in the health care service, for sensorineural symptoms. A group of blue collar workers exposed to vibration in a manufacturing industry (rock crushing plants) was used as the study group. Another group of workers not exposed to vibration but subjected to heavy manual work served as the control group.
\end{abstract}

Methods-Vibrotactile sense was determined. The index and the little fingers of both hands were investigated. A clinical examination was performed. Questionnaires were used for exposure data and for assessment of symptoms.

Results-Important findings were that impairment in vibrotactile sense correlated with impairment in grip force, cold sensitivity, and other sensorineural symptoms-such as numbness and tendency to drop items. Clinical findings such as Phalen's test and two point discrimination were related only in those workers with the poorest vibrotactile sense. There was a relation between vibrotactile sense and the Stockholm workshop scale (sensorineural staging) for the sensorineural symptoms. Muscle and joint problems were more often seen in workers with decreased vibrotactile sense.

Conclusions-Tactilometry for assessment of vibrotactile sense is a useful tool in assessing and evaluating the severity of vibration induced neuromuscular symptoms and verifying the patients'clinical complaints. Heavy manual work without exposure to vibration may contribute to impairment of vibrotactile sense. The relation between impairment in vibrotactile sense and grip strength indicates that impaired sensory feedback may contribute to muscle weakness.

(Occup Environ Med 1997;54:880-887)

Keywords: hand-arm vibration syndrome; sensorineural symptoms; vibrotactile sense

Correspondence to:

Dr Bo T Flodmark,

Svedala-Skuruphälsan $\mathrm{AB}$

Stationsplan 1, S-233 31

Sweden

Fax: 004640401540

Accepted 10 July 1997

Musculoskeletal disorders can result in pain and impaired work performance. The prevalence of extensive muscle fatigue in the hands and arms in forest workers seems to be in the range of $14 \%-35 \%$.' Physiological responses include electrochemical and metabolic changes. These local changes are conveyed to the central nervous system by sensory afferent nerves. ${ }^{2}$ Repetitive muscle contractions, joint positions, and joint movements may induce pressure to the nerves, which ultimately can lead to impaired nerve function. Nerves can also be affected by exposure to vibration. Impairment in nerve function can be reflected in changes in nerve conduction velocity or vibrotactile sense. ${ }^{3-6}$ The maximum hand grip compression correlated significantly with vibrotactile sense and the muscle fatigue process affected mainly the maximum hand grip force. A study by Starck and Toppila" confirmed earlier findings on the importance of grip force to the transmission of vibration. Ákesson et al also noticed a relation between impaired vibrotactile sense and decreased muscle strength in the full hand grip. Vibrotactile sense may be one of the first changes found after exposure to vibration." According to several investigation $\mathrm{s}^{11}{ }^{13}$ the sensorineural component of the hand-arm vibration syndrome develops earlier than the vascular component, white fingers, which has been the most common complaint among workers with many years of exposure to vibration. Lately, there has been a decline in the prevalence of occupational white fingers - for example, among forestry workers using chain saws ${ }^{14}$ - whereas there is increasing interest in the sensorineural symptoms.

Our aim was to study whether vibrotactile sense combined with questionnaires (subjective complaints) and a clinical examination (including scoring on the Stockholm workshop scale (sensorineural staging)) could serve as a screening procedure for sensorineural symptoms in the health care service. A group of blue collar workers exposed to vibration in a manufacturing industry (rock crushing plants) was used as the study group. Another group of workers not exposed to vibration but subjected to heavy manual work served as the control group.

Subjects and methods

The study was performed in a rural community, with about 17000 inhabitants, in the south of Sweden. The study period was from January to the end of April 1993.

SUBJECTS

All male workers exposed to vibration (presently and formerly) in the industry were invited. The control subjects, all men, were subjected to heavy manual work, but without 
Table 1 Subjects in the study (all workers subjected to heavy manual work)

\begin{tabular}{lllll}
\hline Subjects & Participated & Refused & $\begin{array}{l}\text { Excluded for } \\
\text { medical reasons }\end{array}$ & Total number \\
\hline Vibration exposure: & & & & \\
$\quad$ Presently & 71 & 3 & 8 & 82 \\
$\quad$ Formerly & 23 & 3 & 0 & 26 \\
No vibration exposure & 22 & 5 & 5 & 19 \\
Trainees at the workshop school & 19 & 0 & 0 & $159(100)$ \\
Total (n (\%)) & $135(85)$ & $11(7)$ & $13(8)$ &
\end{tabular}

Table 2 Subjects exposed to vibration (\%) and the different types of vibrating tools they have used (some workers used several tools)

\begin{tabular}{lll}
\hline & $\begin{array}{l}\text { Presently exposed to } \\
\text { vibration }(n=71)\end{array}$ & $\begin{array}{l}\text { Previously exposed to } \\
\text { vibration }(n=23)\end{array}$ \\
\hline Grinders & 76 & 87 \\
Chisel hammers & 35 & 61 \\
Impact wrenches & 35 & 22 \\
Drills & 31 & 39 \\
Other types & 15 & 17 \\
\hline
\end{tabular}

exposure to vibration. They were selected, by the secretary of the safety committee, to be the same age as the men exposed to vibration. However, some of the control subjects were found to have been formerly exposed to vibration, so the control subjects were fewer than planned.

The material consisted of the following groups (table 1); (a) heavy manual work and exposure to vibration (presently and formerly), (b) heavy manual work without exposure to vibration, and (c) trainees at the workshop school (as it is interesting to screen people before employment in industry). The mean ages of the participants were; presently exposed to vibration 39.0 (range 20-63) years, formerly exposed to vibration 42.7 (range 23-61), no exposure to vibration 42.5 (range 21-64), and

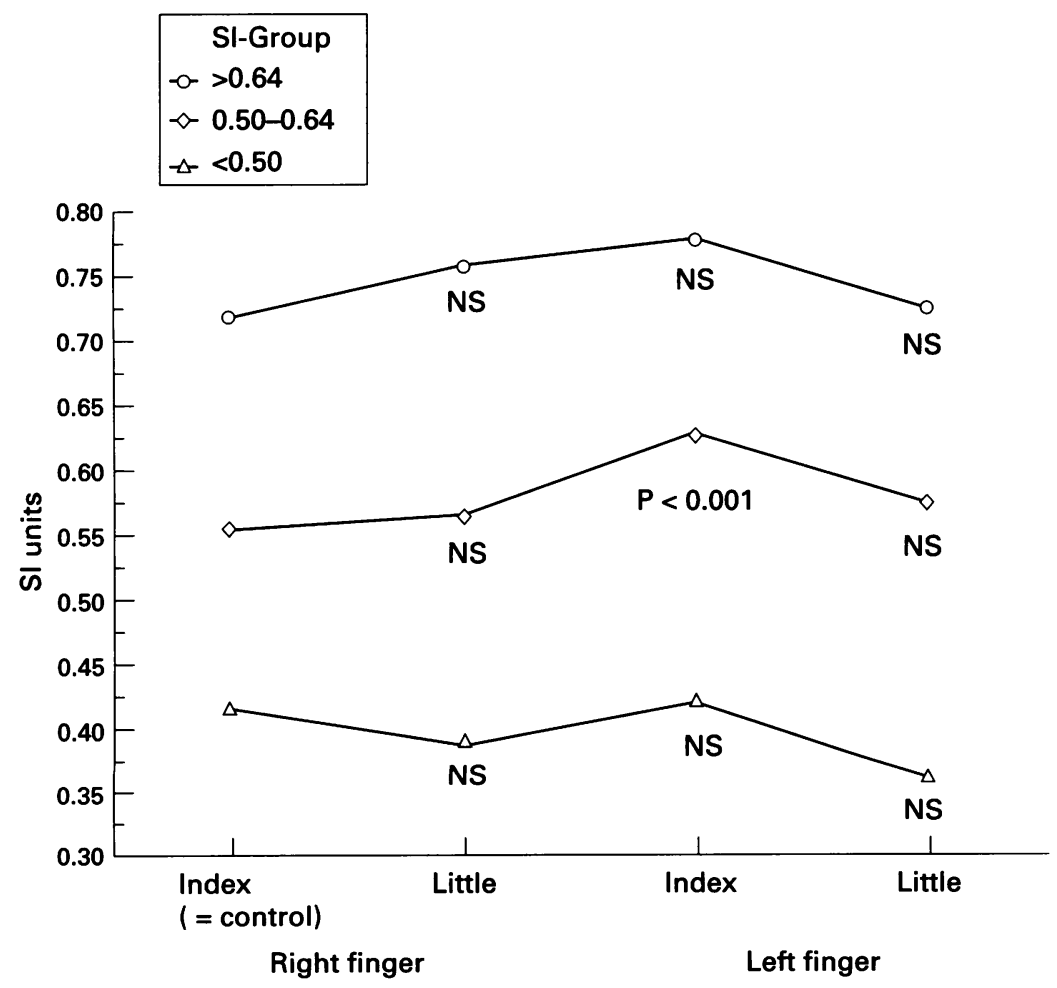

Figure 1 Vibrotactile sense for the four fingers tested among people presently exposed to vibration ( $n=71)$. The results were split into three subgroups $(S I ;>0.64(n=29)$, $0.50-0.64(n=24)$, and $<0.50(n=18))$. Statistics were by Wilcoxon signed rank test (paired test with right index finger as a control). the trainees at the workshop school 17.8 (range 17-19). In total 135 people (85\%) were included of the 159 people invited. The total number of blue collar workers in the industry was 260 .

\section{QUESTIONNAIRES}

A questionnaire ${ }^{15}$ distributed to all participants in the study contained questions about exposure to vibration (years, hours a day), smoking, and nine subjective symptoms (numbness of the hand, grip strength, tendency to drop items, difficulties in handling buttons, pain in the wrist, pain in fingers, cold sensitivity, white fingers, or tremor in hand or arm). White fingers was used irrespective of origin; vibration white finger, Raynaud's disease, or Raynaud's phenomenon of other origin. The questionnaire has been validated ${ }^{16}$ and used by others. ${ }^{17}$ The steps were $1-4$ (1=no symptoms, $2=$ yes insignificant, $3=$ yes some, and $4=y e s$ a lot). Questions were also asked about start of symptoms and occurrence of other diseases which would exclude them from the studysuch as diabetes mellitus, hypertonia, rheumatological diseases, heart disease, hyperthyroidism or hypothyroidism-as well as medication against migraine, hypertonia, or cardiac disease.

No actual measures of exposure to vibration were made for practical reasons as many different vibrating tools (grinders, chisel hammers, impact wrenches, and drills) had been used for many years (table 2). The control subjects were also asked at the medical examination whether they were formerly exposed to vibration or not. The workers exposed to vibration were grouped into exposure categories on the basis of their reported cumulative number of hours of exposure to vibratory tools. ${ }^{18}$ The cut off points selected were 0 and 4800 hours, which correspond to none and the equivalent of 3.0 full time years of use of vibratory tools (eight hours a day and 200 working days a year).

Standardised Nordic questionnaries for the analysis of musculoskeletal symptoms were used. The validity of these has been tested against clinical history (the questionnaire responses were compared with those obtained when a physiotherapist filled out the questionnaire after a thorough interview about medical history). ${ }^{19}$ The main questions were "Have you at any time during the past 12 months had trouble (ache, pain, discomfort) in the; (1) neck? (2) shoulders? (3) elbows? and (4) hands? (yes/no)".

The sensorineural symptoms were graded, at the medical examination, according to the sensorineural staging of the Stockholm workshop scale $^{20}$ (stages; $0,1,2$, and 3 ). The occurrence of vasospastic symptoms was graded according to the vascular staging of the Stockholm workshop scale ${ }^{21}$ (stages; $0,1,2,3$, and 4).

\section{CLINICAL EXAMINATION}

Clinical examination by one of us (BTF) included tests for median nerve function (opposition of thumbs as well as occurrence of Tinel's sign and Phalens's test), ulnar nerve function (abduction or adduction of fingers), 


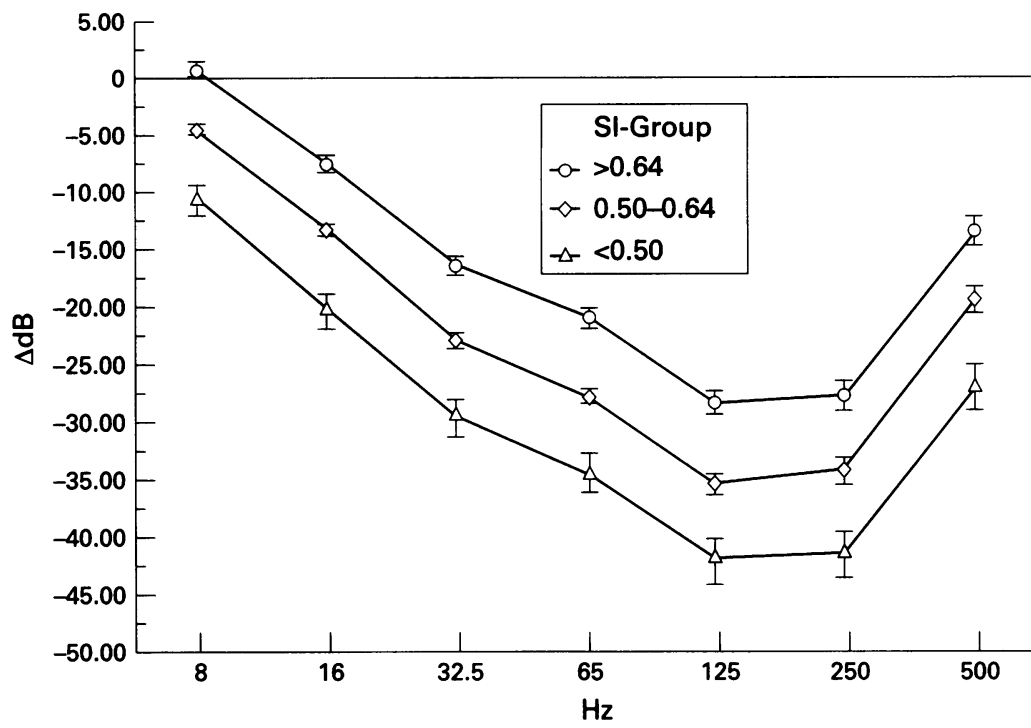

Figure 2 Relative changes in vibrotactile sense (SI) in the tested frequencies $(8-500 \mathrm{~Hz})$ for all workers ( $n=135$ ) (divided into subgroups based on $S I ;>0.64(n=50), 0.50-0.64$ $(n=51)$ and $<0.50(n=34))$ are shown as the difference ( $\triangle d B)$ between each individual test frequency and the age matched reference value. ${ }^{10}$ These figures were normalised to an age of 40 years. Statistics was by Student's $t$ test. Error bars are $95 \%$ CIs.

two point discrimination, and Allen's test for ulnar artery function. ${ }^{15}$

\section{ASSESSMENT OF VIBROTACTILE SENSE}

The vibrotactile sense was determined as previously described by Lundborg et al. ${ }^{322}$ The index and little fingers of both hands were investigated. Briefly, the pulp of the tested finger was allowed to rest against a vibrating probe (a flat topped cylindrical probe with a surface area of $5 \mathrm{~mm}^{2}$ ) placed on top of the vibration exciter. This design, and a different design (the vibration exciter was mounted in a manner similar to a beam balance to provide a constant static pressure of $3.5 \mathrm{~N} / \mathrm{cm}^{2}$ to the skin) gave almost equal results. ${ }^{10}$ The vibration exciter delivered sinusoidal vibrations at seven frequencies ranging from $8-500 \mathrm{~Hz}$. It was driven by a power amplifier controlled by a modified

Table 3 Duration of exposure to vibration in blue collar workers presently exposed to vibration with sufficient data on exposure to vibration versus subjective sensorineural and vascular symptoms

\begin{tabular}{lccc}
\hline Group & $A$ & $B$ & $C$ \\
\hline Full time (equivalent) vibration exposure (y) & $>4$ år & $1-3 \mathrm{arr}$ & 0 år \\
Mean years of 8 h/day with vibration exposuret & $12.6^{\star \star \star}$ & $1.8^{\star \star \star}$ & 0 \\
Number of people & 20 & 29 & 22 \\
SI total (mean) & $0.57 \mathrm{NS}$ & $0.62 \mathrm{NS}$ & 0.63 \\
Symptom scores: & $1.7 \mathrm{NS}$ & $1.8 \mathrm{NS}$ & 1.4 \\
Numbness & $1.7^{\star}$ & $1.5 \mathrm{NS}$ & 1.1 \\
Impaired grip strength & $1.3 \mathrm{NS}$ & $1.4 \mathrm{NS}$ & 1.1 \\
Tendency to drop items & $1.8 \mathrm{NS}$ & $1.9 \mathrm{NS}$ & 1.4 \\
Pain in wrist & $1.7 \mathrm{NS}$ & $1.6 \mathrm{NS}$ & 1.2 \\
Pain in fingers & $1.2 \mathrm{NS}$ & $1.4 \mathrm{NS}$ & 1.0 \\
Difficulties in handling buttons & $1.2 \mathrm{NS}$ & $1.6 \mathrm{NS}$ & 1.1 \\
Tremor in hand or arm & $2.0 \mathrm{NS}$ & $1.7 \mathrm{NS}$ & 1.3 \\
Cold sensitivity & $1.7 \mathrm{NS}$ & $1.5 \mathrm{NS}$ & 1.1 \\
White fingers & & & \\
Stockholm workshop scale: & $0.3 \mathrm{NS}$ & $0.2 \mathrm{NS}$ & 0.0 \\
$\quad$ Vascular staging & $0.5 \mathrm{NS}$ & $0.5 \mathrm{NS}$ & 0.2 \\
Sensorineural staging & $45.3(12.1)$ & $37.0(12.1)$ & $42.5(13.0)$ \\
Background data: & $24.3(11.8)$ & $12.4(9.0)$ & 0 \\
Age (y) & $4.9(2.7)$ & $1.8(1.7)$ & 0 \\
Calendar years with vibration tools & $217(176)$ & $97(110)$ & 0 \\
Mean h/day of vibration exposure & $19.0(15.2)$ & $11.5(8.6)$ & $14.2(10.4)$ \\
Minutes yesterday of vibration exposure & $25.3(3.4)$ & $25.1(2.2)$ & $24.9(3.0)$ \\
Years in current work & & & \\
Body mass index & & &
\end{tabular}

${ }^{\star} \mathrm{P}<0.05 ;{ }^{\star \star} \mathrm{P}<0.01 ; \star \star \star \star \mathrm{P}<0.001$.

$t=$ Also significance between each group $(P<0.001)$. Symptom scoring is $1-4$ (see subjects and methods). For background data mean (SD) are given. version of an audiometer of von Békésy-type. The amplitude within its frequency was regulated by remote control through a button on a hand switch operated by the patient's other hand. Pressing the button caused a gradual decrease in amplitude whereas releasing the button caused an increase. The frequency of the vibration stimulus was automatically changed by the instrument itself in ascending order $(8,16,32.5,65,125,250$, and $500 \mathrm{~Hz}$ ). A vibrogram was obtained, normally with a characteristic shape. Sensory dysfunction was expressed as changes in the shape of the curve, first seen at higher frequencies. Vibrotactile sense was expressed as a sensibility index (SI) ${ }^{23}$ The SI was defined as the ratio between the integrated area under the test curve and the area under an age matched control curve. ${ }^{10}$ An SI of 1.0 indicates equivalent areas below the test curve and the control curve. As vibrotactile perception thresholds increase the vibrogram shifts to a lower position and the SI decreases. It was not practically possible to avoid either vibration or manual work before the tests were performed, as production had to be maintained during working hours. The total test procedure took about 60 minutes when performed by the company nurse. The time interval between the first and the last finger tested was at least 20-30 minutes. All tested people had ear protectors during the test. The room temperature was in the normal ambient range (about $20^{\circ} \mathrm{C}$ ).

\section{STATISTICAL ANALYSIS}

Fisher's exact test was used for determining differences in frequencies; in table 4 the smallest group was 11 people, and in table 6 the smallest group was nine people. The $\chi^{2}$ test for trends ${ }^{24}$ was used for table 5 . Wilcoxon signed rank test was used for comparing the four fingers (the right index finger was the first finger tested and was used as a control) for the vibrotactile sense (fig 1). In fig 2 Student's $t$ test was used. The Mann-Whitney $U$ test (probabilites without correction for ties) was used in tables $3-5$, as the assumptions required to perform a $t$ test were not satisfied in all cases. All tests were two tailed.

\section{Results}

EXPOSURE TO VIBRATION TIME VERSUS VIBROTACTILE SENSE AND SUBJECTIVE SENSORINEURAL AND VASCULAR SYMPTOMS

Table 3 shows the duration of exposure to vibration for those workers with sufficient data presently exposed to vibration versus subjective sensorineural and vascular symptoms. Impaired grip strength was the only symptom which was significant for those with an exposure to vibration of more than four years. There were (with one exception) no significant differences in SI for the four fingers tested (fig 1). A mean value of SI was therefore calculated for all four fingers (SI total).

VIBROTACTILE SENSE VERSUS SENSORINEURAL AND VASCULAR SYMPTOMS

With grouping based on the Stockholm workshop scale (sensorineural staging), in- 
Table 4 Sensorineural and vascular symptoms among workers exposed to vibration ( $n=94 ; 71$ presently exposed and 23 previously exposed to vibration)

\begin{tabular}{|c|c|c|c|}
\hline Group & $A$ & $B$ & $C$ \\
\hline $\begin{array}{l}\text { Grouping based on Stockholm workshop scale } \\
\text { (sensorineural staging) } \\
\text { Scores }\end{array}$ & $\begin{array}{l}\text { Numbness } \\
\text { perpetual } \\
\geqslant 2\end{array}$ & $\begin{array}{l}\text { Numbness } \\
\text { periodically } \\
=1\end{array}$ & $\begin{array}{l}\text { No symptoms } \\
=0\end{array}$ \\
\hline \multicolumn{4}{|l|}{ People (n)‡: } \\
\hline Total & 11 & 21 & 62 \\
\hline Presently exposed & 8 & 18 & 45 \\
\hline Previously exposed & 3 & 3 & 17 \\
\hline SI total (mean) & $0.39^{\star \star \star}$ & $0.55^{\star}$ & 0.63 \\
\hline \multicolumn{4}{|l|}{ Symptom scores: } \\
\hline Numbness & $3.5^{\star \star \star}$ & $2.1^{\star \star \star}$ & 1.1 \\
\hline Impaired grip strength & $2.5^{\star \star}$ & $1.5 \mathrm{NS}$ & 1.2 \\
\hline Tendency to drop items & $2.3^{\star \star}$ & $1.6 \mathrm{NS}$ & 1.1 \\
\hline Pain in wrist & $2.4^{\star}$ & $2.1^{\star}$ & 1.3 \\
\hline Pain in fingers & $2.6^{\star \star \star}$ & $1.9^{\star}$ & 1.1 \\
\hline Difficulties in handling buttons & $1.7 \mathrm{NS}$ & $1.5 \mathrm{NS}$ & 1.1 \\
\hline Tremor in hand or arm & $2.3^{\star}$ & $1.8 \mathrm{NS}$ & 1.3 \\
\hline Cold sensitivity & $2.8^{\star \star}$ & $1.9 \mathrm{NS}$ & 1.5 \\
\hline Vibration white finger & $2.4^{\star}$ & $1.9 \mathrm{NS}$ & 1.3 \\
\hline \multicolumn{4}{|l|}{ Stockholm workshop scale: } \\
\hline Vascular staging & $0.4 \mathrm{NS}$ & $0.5 \mathrm{NS}$ & 0.1 \\
\hline Cold sensitivity & $0.3^{\star}$ & $0.1 \mathrm{NS}$ & 0.1 \\
\hline \multicolumn{4}{|l|}{ Clinical examination: } \\
\hline 2 Point descrimination (mm) & $6^{\star \star}$ & $3 \mathrm{NS}$ & 3 \\
\hline Opposition of fingers: pathological (\%) & $27^{\star \star}$ & $0 \mathrm{NS}$ & 0 \\
\hline Abduction of fingers: pathological (\%) & $18^{\star}$ & $0 \mathrm{NS}$ & 0 \\
\hline Tinel's sign positive (\%) & 45 NS & 29 NS & 19 \\
\hline Phalen's test positive (\%) & $55^{\star \star}$ & 29 NS & 13 \\
\hline Allens' test (\%) & $0 \mathrm{NS}$ & $0 \mathrm{NS}$ & 0 \\
\hline \multicolumn{4}{|l|}{ Background data: } \\
\hline Age (y) & $41.3(10.3)$ & $38.4(11.0)$ & $40.2(13.0)$ \\
\hline Calender years with exposure & $18.8(10.6)$ & $15.4(11.0)(n=20)$ & $14.4(11.9)(n=57)$ \\
\hline Full time ( $8 \mathrm{~h} /$ day) exposure $(y)$ & $8.3(7.9)(n=9)$ & $5.9(8.0)(n=14)$ & $4.9(5.7)(n=46)$ \\
\hline Mean h/day of exposure & $3.6(2.6)(n=9)$ & $3.1(2.5)(n=14)$ & $3.2(2.9)(n=46)$ \\
\hline Minutes yesterday of exposure & $181(193)(n=7)$ & $128(114)(n=14)$ & $156(160)(n=38)$ \\
\hline Calendar years since stopped working with vibrating tools & $2.3(2.4)(n=2)$ & $8.0(7.1)(n=2)$ & $13.2(12.3)(n=16)$ \\
\hline Years in current work & $13.2(13.6)$ & $11.9(10.2)$ & $12.8(11.9)$ \\
\hline Smokers (\%) & 45 & 62 & \\
\hline Body mass index & $26.5(3.4)$ & $25.5(3.2)$ & $25.3(3.5)$ \\
\hline
\end{tabular}

${ }^{\star}=\mathrm{P}<0.05 ;{ }^{\star \star}=\mathrm{P}<0.01 ;{ }^{\star \star \star}=\mathrm{P}<0.001$.

$t=$ Group $A v B$ only $P<0,05$.

$\neq n=11,21$, and 62 in groups $A-C$ if not otherwise stated. Symptom scoring is $1-4$ ( see subjects and methods). For background data mean (SD) are given. Grouping based on Stockholm workshop scale (sensorineural staging). Statistical test is Mann-Whitney $U$ test except for proportions when Fisher's exact test was used. Groups A and B are compared with group C.

creasing severity of sensorineural symptoms in workers exposed to vibration was reflected in an increased tendency for symptoms-such as numbness in the hands and fingers, impaired grip strength, pain in the wrist, pain in the fingers, and tremor in the hands or arms (table 4). The Stockholm workshop scale (sensorineural staging) was related to vibrotactile sense, as were cold sensitivity and white fingers. Only in the group "perpetual numbness", were there signficant clinical findings such as two point discrimination, and pathological findings such as opposition and abduction of fingers.

Table 5 shows various ranges of SI (all blue collar workers and the trainees at the workshop school) are matched against sensorineural, muscular, and vascular symptoms. An important finding was the impaired grip strength with decreased SI. With SI $>0.79$ there were few complaints of nocturnal numbness in the hand whereas such complains occurred increasingly often with decreased SI. Also most of the other sensorineural symptoms followed the same tendency. For SI $<0.50$ there was a high frequency of sensorineural, vascular, and muscular symptoms. Clinical findings were noted mainly in the group with $\mathrm{SI}<0.35$.

CHANGES IN VIBROTACTILE SENSE FOR THE TESTED FREQUENCIES (8-500 HZ)

Changes in vibrotactile sense for the tested frequencies $(8-500 \mathrm{~Hz})$ for all workers $(n=135)$ (divided in subgroups based on SI $>0.64$,
$0.50-0.64$, and $<0.50$ ) are shown as the difference $(\Delta \mathrm{dB})$ between each person's test frequency and the age matched control figure. ${ }^{10}$ These figures were then normalised to an age of 40 years. A lower mean figure of the SI groups gives the results that all tested frequencies $(8-500 \mathrm{~Hz})$ are affected (fig 2).

SMOKING VERSUS VASCULAR AND SENSORINEURAL SYMPTOMS

Table 6 shows the occurrence of vascular and sensorineural symptoms in manual workers exposed to vibration (previously and presently) versus those not exposed to vibration among smokers and non-smokers. In the non-exposed group no cases of white fingers occurred among the non-smokers whereas white fingers were noticed among smokers. All smokers showed higher frequencies of white fingers, cold sensitivity, and impaired grip strength, but the differences were significant only for the workers exposed to vibration. No other sensorineural symptoms reached significance.

\section{Discussion}

EXPOSURE TO VIBRATION VERSUS SENSORINEURAL SYMPTOMS AND VIBRATION WHITE FINGER

There was a clear relation between a lower vibrotactile sense and more pronounced sensorineural symptoms (table 5) and between vibrotactile sense and the Stockholm workshop scale (sensorineural staging), (table 4). This 
Table 5 Vibrotactile sense in a total of 135 people (all blue collar workers exposed to vibration; presently ( $n=71$ ), formerly $(n=23)$, and non-exposed $(n=22)$, and the trainees at the workshop school $(n=19)$ versus subjective sensorineural and vascular symptoms

\begin{tabular}{|c|c|c|c|c|c|c|}
\hline Group & $A$ & $B$ & $C$ & $D$ & $E$ & Pvalue \\
\hline Grouping based on SI total & $<0.35$ & $0.35-0.49$ & $0.50-0.64$ & $0.65-0.79$ & $>0.79$ & \\
\hline SI total (mean) & 0.25 & 0.45 & 0.58 & 0.71 & 0.85 & \\
\hline Number of people (n) & 9 & 25 & 51 & 39 & 11 & \\
\hline \multicolumn{7}{|l|}{ Symptoms (\%): } \\
\hline Numbness (\%) & 78 & 56 & 29 & 15 & 9 & $<0.001$ \\
\hline Impaired grip strength (\%) & 33 & 36 & 14 & 10 & 9 & $<0.01$ \\
\hline Tendency to drop items (\%) & 56 & 28 & 14 & 3 & 0 & $<0.001$ \\
\hline Pain in wrist (\%) & 56 & 44 & 27 & 28 & 18 & $<0.05$ \\
\hline Pain in finger $(\%)$ & 67 & 32 & 20 & 23 & 9 & $<0.01$ \\
\hline Difficulty with buttons (\%) & 33 & 8 & 12 & 8 & 0 & NS \\
\hline Tremor in hand or arm (\%) & 89 & 24 & 18 & 21 & 18 & $<0.001$ \\
\hline \multicolumn{7}{|l|}{ Pain in past year: } \\
\hline $\operatorname{Neck}(\%)$ & 44 & 24 & 10 & 33 & 38 & NS \\
\hline Shoulders (\%) & 56 & 20 & 18 & 36 & 45 & NS \\
\hline Elbows (\%) & 33 & 20 & 10 & 8 & 9 & $<0.05$ \\
\hline Hand $(\%)$ & 56 & 36 & 25 & 21 & 27 & NS \\
\hline Cold sensitivity (\%) & 56 & 32 & 27 & 26 & 27 & NS \\
\hline White fingers (\%) & 44 & 32 & 24 & 13 & 18 & $<0.05$ \\
\hline \multicolumn{7}{|l|}{ Clinical examination: } \\
\hline 2 Point description (mm) & 5 & 3 & 3 & 3 & 3 & \\
\hline Opposition of finger: pathological (\%) & 22 & 4 & 0 & 0 & 0 & $<0.01$ \\
\hline Abduction of finger: pathological (\%) & 22 & 0 & 0 & 0 & 0 & $<0.01$ \\
\hline Tinel's sign positive (\%) & 56 & 28 & 14 & 15 & 9 & $<0.01$ \\
\hline Phalen's test positive (\%) & 67 & 16 & 14 & 15 & 27 & NS \\
\hline Allens' test (\%) & 0 & 0 & 0 & 0 & 0 & NS \\
\hline \multicolumn{7}{|l|}{ Background data: } \\
\hline Age (y) & $35.8(11.5)$ & $41.0(12.8)$ & $37.3(15.0)$ & $34.8(13.7)$ & $38.3(14.0)$ & \\
\hline Body mass index & $25.5(4.5)$ & $26.4(3.1)$ & $24.9(3.2)$ & $24.6(3.4)$ & $24.4(3.1)$ & \\
\hline Smokers(\%) & 56 & 56 & 49 & 51 & 36 & \\
\hline
\end{tabular}

Groups are divided according to the results of the SI and all groups are significantly different from each other (Mann-Whitney $U$ test $\mathrm{P}<0.001) \cdot \chi^{2}$ for trends were used for frequencies. For background data means (SDs) are given.

finding and it is also supported by the results of Yamada et $a .^{25}$ The relation was not so pronounced for cold sensitivity and white fingers.

Results from an epidemiological study indicated that there may be an exposure-response relation for exposure to vibration and neurological disturbances. ${ }^{12}$ In our study there was no clear correlation between time of exposure to vibration and changes in vibrotactile sense (table 3) but there was a trend when grouping was based on the Stockholm workshop scale (sensorineural staging, table 4). The explanation may be that the questionnaires, although they have been validated, are not very good for assessment of time of exposure to vibration. The possibility that the vibrotactile sense is affected early in exposure may be an explanation for the findings that there was no significance difference between the mean SI for all the groups exposed to vibration and the non-exposed groups. Many factors may help to explain this finding such as individual variations in vulnerability to vibration trauma, variations in working technique and grip force around the tool, and variations in type of hard manual work, which also may affect the transmission of vibration to the hand.

Table 6 Smoking in blue collar workers not exposed and previously and presently exposed to vibration versus vascular and sensorineural symptoms

\begin{tabular}{lllll}
\hline Symptom & Exposure & Non-smokers (\%) & Current smokers (\%) & P value \\
\hline White fingers & $\begin{array}{l}\text { Non-exposed } \\
\text { Previously and }\end{array}$ & $0(\mathrm{n}=9)$ & $23(\mathrm{n}=13)$ & NS \\
& $\begin{array}{l}\text { presently exposed } \\
\text { Cold sensitivity }\end{array}$ & 11 & $38(\mathrm{n}=45)$ & $<0.05$ \\
& $\begin{array}{l}\text { Non-exposed } \\
\text { Previously and }\end{array}$ & 11 & 23 & NS \\
& $\begin{array}{l}\text { presently exposed } \\
\text { Impaired grip strength }\end{array}$ & 0 & 49 & $<0.01$ \\
& $\begin{array}{l}\text { Non-exposed } \\
\text { Previously and } \\
\text { presently exposed }\end{array}$ & 14 & 8 & NS \\
& & 33 & $<0.05$ \\
\hline
\end{tabular}

Frequencies (\%) of symptoms (according to questionnaires). Statistics by Fisher's exact test.
It was not possible to establish a valid quantitative relation between sensorineural disturbances and exposure to vibration. ${ }^{131426}$ Perhaps the lack of this relation could be explained by the healthy worker effect, as a very healthy worker may tolerate exposure to vibration much better than an average worker. The healthy worker effect has been known for more than 100 years, but the term first appeared in print in $1974 .{ }^{27}$ It comprises the healthy hire effect, the healthy worker survivor effect, and the decline in health with time since hire. ${ }^{28}$ Changes in lifestyle (improved economic status, better access to medical care, and changes in lifestyle) accompanying employment should also be included. ${ }^{29}$ Ohlson $e t a^{\beta 0}$ found that among assembly workers those who worked fastest had a lower prevalence of musculoskeletal symptoms of the neck and hand-arm system. Interestingly, the group with the longest exposure to vibration sometimes gives unexpectedly good results. According to table 3 a healthy worker effect may exist. The mean SIs are about the same in the groups exposed to vibration (table 3). Letz et al $^{18}$ found that there were no further increases in reporting sensorineural symptoms in workers with more than 17000 hours of exposure to vibratory tools. However, the healthy worker effect has seldom been discussed for hand-arm vibration. ${ }^{14}$

IMPAIRED GRIP STRENGTH

A two year follow up study on the hand grip force in lumberjacks ${ }^{31}$ suggested that long term exposure to vibration causes a decrease in muscle force, and not only in laboratory experiments. ${ }^{32}{ }^{33}$ Decreased grip strength and a correlation with vibrotactile sense was also found in a study of 462 chainsaw operators. ${ }^{25}$ 
It is important to find the frequencies which may have serious effects on the musculoskeletal symptoms. Low frequencies $(<50 \mathrm{~Hz})$ are mainly transmitted to the hand and the forearm, whereas higher frequencies are mostly absorbed by the hand. ${ }^{14} \mathrm{~A}$ study by $\mathrm{Okada}^{34}$ showed that after vibrating the hind legs of a rat, the activity of plasma creatine phosphokinase was significantly increased at 30,60 , 120,240 , and $480 \mathrm{~Hz}$ and was especially high at $30 \mathrm{~Hz}$.

The transmission of vibration may be dependent on body weight ${ }^{35}$ but we did not find any correlation in our study (tables 3-5) when using the more accurate body mass index (BMI).

Vibration induced muscle injury in the hind limb of rats has been shown by Necking et al. ${ }^{36}$ When the hind limb was subjected to vibration over periods of two to five days early signs of muscle fibre degeneration were noticed as an increased frequency of internal nuclei in the muscle fibres ${ }^{37}$ as well as changes in the muscle fibre area.

Martin and Armstrong presented a model to describe the way in which vibration induced alterations of motor control may cause or aggravate musculoskeletal and peripheral nerve disorders. $^{38}$

The relation between impairment in vibrotactile sense and grip strength indicates that impaired sensory feedback may contribute to muscle weakness. The results of our findings with higher frequencies of impaired grip strength in the hands (table 4) in blue collar workers exposed to vibration are in accordance with these studies.

\section{COLD SENSITIVITY}

The results in table 4 show a relation between cold sensitivity and white fingers in the group with the lowest SI values (mean 0.39). The symptom cold sensitivity (or cold intolerance) is often experienced as a vascular problem. The decreased occurrence of cold sensitivity parallel to the increased occurrence of white fingers after 11 to 20 years of exposure (fig 3 in the study by Strömberg $e t a l^{13}$ indicates that cold sensitivity may be a pre-stage of white fingers). Our groups were not large enough to support such conclusions.

\section{VIBROTACTILE SENSE}

In a study on 171 healthy men ${ }^{10}$ not exposed to vibration or hard manual work, SI was considerably higher $(>0.80)$ than in our study. Not only vibration but also manual work may affect vibrotactile sense (see the unexposed group with an SI mean of 0.63 , table 3 ). A possible explanation may be a subclinical level of interference with the median nerve at wrist level induced by hard manual work. ${ }^{39}$

Our results indicate that an SI of $0.50-0.64$ may be a critical range, as when SI is $<0.50$ there is a clear rise in frequencies of sensorineural symptoms.

In the study by Lundborg et $a l^{23}$ a high (83\%) incidence of sensorineural symptoms was noted for all four fingers tested in patients with brachialgia $(n=30)$ without any obvious cause, but also in workers exposed to vibration $(n=146,53 \%)$. This is in line with our results (fig 1).

Neurophysiological studies have shown that most of the increase in tactile perception threshold involves peripheral receptor mechanisms. ${ }^{14}$ The earliest sign of decreased vibrotactile sensation is a flattening of the peak of the curve of the vibrogram. In more advanced stages both higher and lower frequencies are decreased. ${ }^{3}$ Figure 2 shows that all tested frequencies were affected. When a correlation was made between different biological factors of the subjects' hand-arm systems and the mechanical impedance as a function of the frequency, in the frequency range of about 200 to $300 \mathrm{~Hz}$ where the impedance has a low point, the highest correlation was found for the grip force applied by the subject. ${ }^{40} \mathrm{~A}$ comparison of single $(100 \mathrm{~Hz})$ and multifrequency $(8-500 \mathrm{~Hz})$ tactilometry with neurological symptoms was made by Wenemark et $a l .{ }^{17}$ The results showed a relation (not very strong) between the instruments used, but there were technical differences such as probe size and contact force that may have influenced the results. According to our results (fig 2) it seems most appropriate to use a multifrequency method. This is also desirable from a neurophysiological point of view. ${ }^{41}$

In compression neuropathies changes in vibrotactile sense are early signs, always appearing before changes in two point discrimination and often appearing before impairement in nerve conduction velocity. ${ }^{11} \mathrm{We}$ found pathological two point discrimination only in the group with the lowest vibrotactile sense (SI mean 0.39 (table 4)). Many investigators have found a modest relation between vibrotactile thresholds and nerve conduction measurements. The results indicated that vibrotactile thresholds do not measure the same neurological attributes as nerve conduction velocity and electromyography, and thus are not fully equivalent to electrophysiological evaluation. ${ }^{642}$

There is no systematic influence of time of day on vibration sensation threshold. ${ }^{43}$ Vibrotactile thresholds are not affected by skin temperature over the range usually encountered in study subjects tested at normal ambient temperature. ${ }^{42}$ There is no correlation between skin thickness and vibration perception threshold. ${ }^{44}$

Alcohol consumption is commonly presumed to affect neurological performance and measurement of vibrotactile threshold. Only those subjects with serious social or medical consequences of ethanol consumption have been found to have increased vibrotactile thresholds. $^{42}$ It can be of only minor importance in this study, as the company nurse (industrial health care service) has had knowledge of all the blue collar workers for more than 30 years (most of them live in the same small town). Most of the workers were skilled men doing a heavy job, which would have been impossible if they were alcoholics.

The use of tobacco seems to aggravate the symptoms of white finger and to result in 
increased reactivity in a cold provocation test. ${ }^{45}$ According to Nilsson $e t a l^{46}$ nicotine is of minor importance relative to exposure to vibration. Letz et $a l^{18}$ noticed that smoking was signficantly related to vascular and sensorineural symptoms but age was not. Our study gives some support to the negative effects of smoking on white finger, cold sensitivity, and impaired grip strength (table 6).

STOCKHOLM WORKSHOP SCALE (SENSORNEURAL STAGING) AND CLINICAL EXAMINATION

Table 4 shows that the clear differences in mean SI for the different stages could actually serve as a validation of the Stockholm workshop scale. This staging seems to be more sensitive than the clinical examination, as a clinical examination identifies only the pathological symptoms found in the most severe cases and is not sensitive enough to prevent vibration related injuries.

\section{CONSIDERATIONS OF STUDY DESIGN AND BIAS}

There are several considerations involving potential bias in a cross sectional study. As 7\% of the study participants refused to participate in all parts of the study, the prevalences of the symptoms reported for the responders are biased estimates of the true prevalences among the entire population. However, this bias is of minor importance as we have complete data from $93 \%$ of the group. The exclusion of people with medical conditions that cause symptoms similar to hand-arm vibration syndrome would cause underestimation of the prevalence of disease. However, only 13 people (8\%) were excluded because of such a disease or medication. As not only active workers were studied, but also those formerly exposed to vibrating tools (with the exception to the few who had left the industry), the figures should be fairly accurate. There is a lack of exact data on exposure to vibration, but as the workers had been working with many different tools (table 2) for between one and 47 years, a questionnaire is a compromise. The participants may have overreported symptoms as they were aware of the purpose of the study. The agreement between the objective vibrotactile sense and subjectively reported symptoms (table 5) argue against the symptoms having been overreported. Impaired hand grip was only measured by questionnaries, which is a weakness in the study. All questionnaires have been validated.

Non-parametric statistical tests were mostly used because of small sample size and skewed distributions. Mean values are given for symptom scores despite a rank scale being used. The problems this raises have been discussed, ${ }^{47}$ as it can both overestimate and underestimate the true figures. This cannot be the only explanation for the results showing relation between vibrotactile sense and sensorineural symptoms (table 4 and 5). The results are also unlikely to occur from so called mass significance as our results accord with what would be expected and other research. ${ }^{25}$

Normally there is only one vibrotactile sense test per person in a cross sectional study like this, but as we used the mean of the four fingers tested (SI total), the results at least at a group level still can be of value. The SI as used in this study followed the standard description. ${ }^{23}$

\section{Conclusions}

The relation between impairment in vibrotactile sense and grip strength indicates that impaired sensory feedback may contribute to muscle weakness. We think that the SI is a useful tool in assessing vibrotactile sense and evaluating the severity of sensorineural symptoms induced by vibration and in verifying the patients' clinical complaints. Vulnerability to vibration trauma may vary considerably from person to person, and the technique is probably most valuable on an individual basis in the long term to verify or exclude the development of nerve injury induced by vibration. Ideally there must be measures of the combination of exposure to vibration and all other biological factors affecting the hand-arm system. The SI could be such a measure for distal hand-arm symptoms.

Research into vibration injuries in the Department of Hand Surgery, Malmö University Hospital, Lund University is supported by the Swedish Council for Work Life Research, Stockholm. We thank the workers, the managers at the plant, and the company nurse Lisbeth Ohlander, who made this study possible.Thanks also to Jan-Åke Nilsson, Department of Information Technology, University Hospital MAS, Malmö, Sweden, for statistical discussions.

1 Pyykkö I. Clinical aspects of the hand-arm vibration syndrome. A review. Scand $f$ Work Environ Health 1986;12:439-47.

2 Armstrong TJ, Buckle P, Fine LJ, Hagberg $M$, Jonsson B Kilbom A. A conceptual model for work-related neck and upper-limb muskuloskeletal disorders. Scand $\mathcal{f}$ Work Environ Health 1993;19:73-84.

3 Lundborg G, Sollerman C, Strömberg T, Pyykkö I, Rosén B. A new principle for assessing vibrotactile sense in vibration-induced neuropathy. Scand $\mathcal{F}$ Work Environ Health 1987;13:375-9.

4 Brammer AJ, Piercy JE, Auger PL, Nohara S. Tactile perception in hands occupationally exposed to vibration. $f$ perception in hands occupationaly

5 Brammer AJ, Pyykkö I. Vibration-induced neuropathy. Detection by nerve conduction measurements. Scand $\mathcal{F}$ Work Environ Health 1987;13:317-22.

6 Franzblau A, Werner RA, Johnston E, Torrey S. Evaluation of current perception threshold testing as a screening procedure for carpal tunnel syndrome among industrial workers. F Occup Med 1994;36:1015-21.

7 Pyykkö I, Inaba R, Koskimies K, Starck J, Färkkilä $M$, Aatola $S$. Vibration-induced muscle fatigue among forest workers. Proceedings of 6 th International Conference on HandArm Vibration, May 19-22. Bonn: Hauptverband der gewArm Vibration, May 19-22. Bonn: Hauptverband der gew-

8 Starck J, Toppila E. Influence of hand dimension and grip force on vibration transmission into the hand. In: Gemne G, Brammer AJ, Hagberg M, Lundström R, Nilsson T, eds. Proceedings of the Stockholm Workshop 94. Hand-arm vibration syndrome: diagnostics and quantitative relationships to exposure. National Institute for Working Life Solna, Sweden. Arbete och Hälsa 1995;5:137-42.

9 Ákesson I, Lundborg G, Horstmann V, Skerfving S Neuropathy in female dental personnel exposed to high frequency vibrations. Occup Environ Med 1995;52:116-23.

10 Lundström R, Strömberg T, Lundborg G. Vibrotactile perception threshold measurements for diagnosis of sensory neuropathy. Description of a reference population. Int Arch neuropathy. Description of a reference

11 Brammer AJ, Taylor W, Piercy JE. Assessing the severity of the neurological component of the hand-arm vibration syndrome. Scand $₹$ Work Environ Health 1986;12:428-31.

12 Lundström $R$, Hagberg $M$, Johansson $K$, Lindmark $A$, Nilsson $\mathrm{T}$. Handens känselfunktion hos plåtslagare och montörer utsatta för vibrationer. National Institute for Working Life, Umeå and Solna, Sweden. Arbete och Hälsa 1991;42. (In Swedish. Abstract in English.)

13 Strömberg T, Dahlin LB, Lundborg G. Hand problems in 100 vibration-exposed symptomatic male workers. $\mathcal{f}$ Hand Surg $(B r)$ 1996;21:315-9.

14 Gemne G, Lundström R, Hansson J-E. Disorders induced by work with hand-held vibrating tools. A review of curren knowledge for criteria documentation. National Institute for Working Life, Umeá, Sweden. Arbete och Hälsa 1993;6. 
15 Ekenvall L, Hagberg M, Lundborg G, Lundström R. Att förebygga vibrationsskador. (To prevent vibration injuries.) The Swedish Council for Work Life Resea
Sweden. Rapportserien 1991. (In Swedish.)

16 Johansson K, Hagberg M. Riskidentifiering av vibrationsrelaterade handbesvär - validitetsaspekter på frågeformulär. National Institute for Working Life, Solna, Sweden. Arbete och Hälsa 1990;13. (In Swedish. Abstract in English.)

17 Wenemark M, Lundström R, Hagberg M, Nilsson T. Comparison of single and multi-frequency vibrotactile perception threshold measurements. In: Gemne G, Brammer AJ, Hagberg M, Lundström R, Nilsson T, eds. Proceedings of the Stockholm Workshop 94. Hand-arm vibration syndrome: diagnostics and quantitative relationships to exposure. National Institute for Working Life, Solna, Sweden. Arbete och Hälsa, 1995;5:157-60.

18 Letz R, Cherniack MG, Gerr F, Hershman D, Pace P. A cross sectional epidemiological survey of shipyard workers exposed to hand-arm vibration. $B r f$ Ind Med 1992;49:5362 .

19 Kuorinka I, Jonsson B, Kilbom $\AA$, Winterberg H, BieringSørensen F, Andersson G. Standardised nordic questionnaries for the analysis of musculoskeletal symptoms. Applied Ergonomics 1987;18:233-7.

20 Brammer AJ, Taylor W, Lundborg G. Sensorineural stages of the hand-arm vibration syndrome. Scand $\mathcal{f}$ Work Environ Health 1987;13:279-83.

21 Gemne G, Pyykkö I, Taylor W, Pelmear PL. The Stockholm workshop scale for the classification of cold-induced Raynaud's phenomenon in the hand-arm vibration syndrome (revision of the Taylor-Pelmear scale). Scand 7 Work drome (revision of the Taylor-P
Environ Health 1987;13:275-8.

22 Lundborg G, Lie-Stenström A-K, Sollerman C, Strömberg T, Pyykkö I. Digital vibrogram: a new diagnostic tool for sensory testing in compression neuropathy. $\mathcal{F}$ Hand Surg (Am) 1986;11:693-9.

23 Lundborg G, Dahlin LB, Lundström R, Necking LE, Stromberg $T$. Vibrotactile function of the hand in compression and vibration-induced neuropathy. Sensibility index-a new measure. Scand $¥$ Plast Reconstr Hand Surg 1992; 26:275-9.

24 Altman DG. Statistical methods in medical research. New York: John Wiley, 1980:363.

25 Yamada S, Sakakibara H, Futatsuka M. Examination results, subjective symptoms, and stages of vibration syndrome. In: Gemne $G$, Brammer AJ, Hagberg $M$, Lundström $R$, Gemne G, Brammer AJ, Hagberg M, Lundström R,
Nilsson T, eds. Proceedings of the Stockholm Workshop 94. Nilsson T, eds. Proceedings of the Stockholm Workshop 94. Hand-arm vibration syndrome: diagnostics and quantitative
relationships to exposure. National Institute for Working Life, relationships to exposure. National Institute for Wor
Solna, Sweden. Arbete och Hälsa 1995;5:165-70.

26 Anonymous. The quantitative relationships between exposure and disturbances induced by hand-arm vibrationstatement. In: Gemne G, Brammer AJ, Hagberg M, Lundström R, Nilsson T, eds. Proceedings of the Stockholm Workshop 94. Hand-arm vibration syndrome: diagnostics and quantitative relationships to exposure. National Institute for Working Life, Solna Sweden Arbete och Hälsa 1995;5:199.

27 Weed DL. Historical roots of the healthy worker effect. $f$ Ocupc Med 1986;28:343-7.

28 Arrighi HM, Hertz-Picciotto I. The evolving concept of the healthy worker survivor effect. Epidemiology 1994;5:18996.

29 Wen CP, Tsai SP, Gibson RL. Anatomy of the healthy worker effect: a critical review. F Occup Med 1983;25:2839.

30 Ohlsson K, Attewell R, Skerfving S. Self-reported symptoms in the neck and upper limbs of female assembly workers.
Impact of length of employment, work pace and selection. Scand 7 Work Environ Health 1989;15:75-80.

31 Färkkilä M, Aatola S, Starck J, Korhonen O, Pyykkö I Hand-grip force in lumberjacks: a two-year follow-up. Int Arch Occup Environ Health 1986;58:203-8.

32 Färkkilä $M$. Grip force in vibration disease. Scand $\mathcal{f}$ Work Environ Health 1978;4:159-66.

33 Färkkilä M, Pyykkö I, Karhonen O, Starck J. Vibrationinduced decrease in the muscle force in lumberjacks. Eur $\mathcal{F}$ Appl Physiol 1980;43:1-9.

34 Okada A. Physiological response of the rat to different vibration frequencies. Scand $f$ Work Environ Health 1986;12:362-4.

35 Rohmert W, Wos H, Norlander S, Helbig R. Effects of vibration on arm and shoulder muscles in three body postures. Eur F Appl Physiol 1989;59:243-8

36 Necking LE, Dahlin LB, Fridén J, Lundborg G, Lundström $R$, Thornell LE. Vibration-induced muscle injury. An experimental model and preliminary findings. 7 Hand Surg (Br) 1992;17:270-4.

37 Necking LE, Lundström R, Lundborg G, Thornell L-E, Fridén J. Skeletal muscle changes after short term vibration. Scand $\mathcal{F}$ Plast Reconstr Hand Surg 1996;30:90103.

38 Martin BJ, Armstrong TJ. Contribution of vibrationinduced alterations of neurosensory mechanisms to tissue stress and muscle fatigue-a conceptual model. In: Gemne G, Brammer AJ, Hagberg M, Lundström R, eds. Proceedings of the Stockholm Workshop 94. Hand-arm vibration syndrome: diagnostics and quantitative relationships to exposure. National Institute for Working Life, Solna, Sweden. Arbete och Hälsa 1995;5:97-108.

39 Hagberg M, Morgenstern H, Kelsh M. Impact of occupations and job tasks on the prevalence of carpal tunnel syn-
drome. Scand $\mathcal{F}$ Work Environ Health 1992;18:337-45.

40 Burström L. Meaurements of the impedance of the hand and arm. Int Arch Occup Environ Health 1990;62:431-9.

41 Anonymous. Clinical and laboratory diagnostics of neurological disturbances in workers using hand-held vibrating tools. Report form discussions in a working group. In: Gemne G, Brammer AJ, Hagberg M, Lundström $\mathrm{R}$, Nilsson T, eds. Proceedings of the Stockholm Workshop 94. Hand-arm vibration syndrome: diagnostics and quantitative relationships to exposure. National Institute for Working Life, Solna, Sweden. Arbete och Hälsa 1995;5:187-94.

42 Gerr F, Letz R. Vibrotactile threshold testing in occupational health: a review of current issues and limitations. Environ Res 1993;60:145-59.

43 Ess G, Dupuis H. Intraindividual variability of vibration sensitivity at the finger tips. Proceedings of 6th International Conference on Hand-Arm Vibration, Bonn. Hauptverband der gewerblichen Berufsgenossenschafen (HBG) 1992: 291-6.

44 Collier A, Patrick AW, Bell D, Matthews DM, MacIntyre CCA, Ewing DJ. Relationship of skin thickness to duration of diabetes, glycemic control, and diabetic complications in male IDDM patients. Diabetes Care 1989;12:309-12.

45 Ekenvall L, Lindblad LE. Effect of tobacco use on vibration white finger disease. $\mathcal{F}$ Occup Med 1989;31:13-6.

46 Nilsson T, Burström L, Hagberg M. Risk assessment of vibration exposure and white fingers among platers. Int vibration exposure and white fingers among
Arch Occup Environ Health 1989;61:473-81.

47 Coste J, Fermanian J, Venot A. Methodological and statistical problems in the construction of composite measurement scales: a survey of six medical and epidemiological journals. Stat Med 1995;14:331-45.

\section{Rejected manuscripts}

From February 1994, authors whose submitted articles are rejected will be advised of the decision and one copy of the article, together with any reviewer's comments, will be returned to them. The fournal will destroy remaining copies of the article but correspondence and reviewers' comments will be kept. 